\title{
Observational learning and willingness to pay in equity crowdfunding
}

\author{
Martin Walther ${ }^{1} \cdot$ Marco Bade $^{1}$
}

Received: 22 July 2019/Accepted: 17 December 2019/Published online: 7 January 2020

(C) The Author(s) 2020

\begin{abstract}
This study examines interdependencies between investments of equity crowdfunders. Based on hand-collected data from a well-established equitycrowdfunding platform, we find strong indication that investors observe previous investments to determine their willingness to pay for equity shares. Furthermore, the investment behavior of predecessors may lead investors to deviate from average investment behavior. In particular, investors are willing to pay more than the average investment, when the focal campaign is hot or there have been many large investments in the campaign. Remarkably, a high number of all previous investments over the entire period of the campaign as well as co-financing by presumably sophisticated investors negatively influence willingness to pay. This suggests that crowd investors are subject to partial crowding-out. These findings are different on the platform level, which suggests that investors' behavior is rather information than sentiment-driven.
\end{abstract}

Keywords Equity crowdfunding · Observational learning · Crowding out - Investment interdependencies · Individual investment behavior

Marco Bade

marco.bade@tu-berlin.de

Martin Walther

martin.walther@tu-berlin.de

1 Technische Universitaet Berlin, Chair of Finance and Investment, Sec. H 64, Straße des 17. Juni 135, 10623 Berlin, Germany 


\section{Introduction}

Two of the most important questions entrepreneurs face in crowdfunding are how to get crowdfunders to invest in their campaign and how to make them invest as much as possible. The first question has been studied in the recent past (e.g., Ordanini et al. 2011; Schwienbacher and Larralde 2012; Burtch et al. 2013; Cumming and Johan 2013; Gerber and Hui 2013; Hong et al. 2015). To address the second question, entrepreneurs have to understand which factors influence the investment volumes of crowdfunders. This paper aims to contribute to this growing literature and investigates the factors influencing crowdfunders' willingness to pay for equity shares. In particular, we focus on interdependencies between investments by considering several observables related to previous investments. We, therefore, examine the questions of what motivates an investor to deviate from the typical investment behavior on the platform, and what role conspicuous investment behavior of predecessors plays.

Consider an entrepreneur starting a venture with an innovative service or product. In many cases, traditional funding, such as bank loan, is not feasible due to uncertainty concerning venture success. In addition, before raising venture capital for growth, early-stage funding is required. This is where crowdfunding as a complement to other funding sources typically comes into play.

The procedure is as follows: the entrepreneur designs a campaign (including venture/product/service description, entrepreneurial team description, goal amount, business plan, etc.) and approaches a crowd of investors via a crowdfunding platform. On many platforms, crowdfunding outcomes are binary. If the campaign reaches its predetermined funding goal, it is successful. Otherwise, the campaign fails and funders are refunded. Successful crowdfunding before tapping other financiers is critical to venture success, as it signals public interest, provides early feedback on venture quality as well as customer preferences, and raises capital entrepreneurs can only access after funding goals are met (Babich et al. 2018). Hence, understanding funders' behavior is a crucial success factor for entrepreneurs.

Our paper focuses on equity crowdfunding, which “... is a form of financing in which entrepreneurs make an open call to sell a specified amount of equity or bondlike shares in a company on the Internet, hoping to attract a large group of investors" (Ahlers et al. 2015, p. 955). In contrast to reward-based crowdfunding, in equity crowdfunding funders do not (pre-)order products at a given price but determine independently the amount they want to invest for shares in the venture. The prior decision on whether to invest in a campaign depends on factors such as geographic proximity (Agrawal et al. 2015), signals of quality, and electronic word of mouth (e.g., word count of the project description, video count, and "likes" or comments/reviews by other funders). These factors positively influence investment decisions (Bi et al. 2017; Hornuf and Schwienbacher 2018). In addition, funders seem to consider financial roadmaps, risk factors, and the quality of internal governance (Ahlers et al. 2015).

If an investor has classified a company as suitable and has decided to invest, the amount of investment is selected. The determination of the individual investment 
volume may again depend on some of the factors mentioned but even more on the actual behavior of other investors. The actual behavior is a more credible signal than reviews and comments by others, as these are subject to confirmation bias (Chapman and Johnson 2002). The questions investors ask themselves are, for example: how much do others invest? How many investors have already invested? How hot is the campaign compared to other campaigns on the platform? Are there noticeably many large investments? This can be used to deduce both some of the private information of others and the probability of success of the campaign. In psychology, the influence resulting from the processing of information gained by observing others is called "observational" or "social learning" (Bandura 1977). This may lead to interdependencies between investments. These are the main subject of our paper. We examine the factors that motivate investors to deviate from the typical investment behavior on a platform, particularly based on observing conspicuous previous investments.

We find that investors are willing to pay more than the average investment amount when the focal campaign is hot compared to other campaigns. In addition, investors tend to contribute more if there have been many large investments before-both over the entire period of the campaign and in the past few days. Remarkably, a high number of all previous investments over the entire period since the start of the campaign as well as the existence of presumably sophisticated cofinanciers negatively influence willingness to pay. This suggests that crowd investors are subject to partial crowding-out. After all, our results indicate that conspicuous investment behavior of predecessors may lead to deviations in the investment behavior of subsequent investors. We further find indication that investors' behavior is rather information-driven than sentiment-driven.

The remainder of the paper is organized as follows. Section 2 discusses related literature. In Sect. 3, we outlay the theoretical background for our analysis. In addition, we develop our hypotheses. Section 4 presents our empirical setting and describes the sample construction. Furthermore, we present descriptive statistics for our dataset. In Sect. 5, we describe the econometric model. Section 6 discusses the results. In Sect. 7, we conclude the paper.

\section{Related literature}

Our study is most closely related to Åstebro et al. (2018), who examine rational herding on the UK-based equity-crowdfunding platform "SEEDRS". Most importantly, they find a positive impact of the size of recent investments and a negative impact of the time elapsed since the most recent investment on both the size and the likelihood of an investment. Their results suggest that investors observe previous investments to overcome information asymmetries and alter their investment strategies. The authors capture information asymmetry via the types of investors. Sophisticated and recurrent backers are assumed to be better informed than single-campaign investors or investors who did not report to be sophisticated or high-net-worth investors in their profile. Our study complements this research in three ways. First, by considering friends-and-family investors and geographical 
distance (local bias), we control for other essential drivers of investment behavior. Second, we capture information asymmetry in a different way, particularly by differentiating between supposedly better informed local investors and distant ones. Third, by taking a platform-based point of view, we carry out an additional analysis to check whether information or sentiment drives investments.

In line with Åstebro et al. (2018) and based on an experimental approach, Bursztyn et al. (2014) find evidence that social learning and social utility affect investment decisions. Their results suggest that investors look at their peers and update their beliefs. Social learning is more present when the first investor is financially sophisticated or when the second investor is unsophisticated. This study focuses on both investment probability and the quantity of a purchased asset.

Motivated by empirical evidence on rational herding in financial markets, Cong and Xiao (2018) build a theoretical model, which links herding and crowdfunding. They demonstrate that an all-or-nothing rule causes agents to rationally ignore private signals and, instead, imitate previous investors only when those supported the venture. This means that the implementation of an all-or-nothing rule can prevent abstention cascades from taking place. Note that the platform we consider uses such a rule.

Zhang and Liu (2012) identify rational herding in peer-to-peer lending. They find that listings of well-funded borrowers are more successful in attracting funding. In addition, lenders observe decisions and public characteristics of other lenders to infer the creditworthiness of borrowers. The dependent variable in their main analysis is the amount of funding that a specific listing receives each day.

Our study is further related to the more general literature on the drivers of individual investment behavior. This stream of research examines different dependent variables. Agrawal et al. (2015) as well as Lin and Viswanathan (2016) analyze investment probability. Agrawal et al. (2015) use data from a reward-based/donation-based crowdfunding platform called "SellaBand", on which funders can support musicians. They find that local funders are less sensitive to information on cumulative investments. However, friends-and-family investors explain this effect to a large extent. Given the strong influence of friends and family, we also pay attention to these investors in our analyses. Lin and Viswanathan (2016) use a quasi-experimental design to provide evidence on the existence of local bias in peer-to-peer lending. They argue that information asymmetries cannot fully explain local bias, which means that behavioral anomalies, such as the familiarity bias, are likely to drive local bias at least partially. Our study contributes to the literature on investment interdependencies in crowdfunding by considering the existence of local bias as well as information asymmetries resulting from geographical distance.

Ahlers et al. (2015) focus on the number of investors and the total amount of funds raised. They find that retaining equity and the provision of plentiful information on risks positively affect venture success, implying that these are effective signals of venture quality.

The number of (daily) backers is studied by, for example, Kuppuswamy and Bayus (2017, 2018), and Hornuf and Schwienbacher (2018). Kuppuswamy and Bayus (2017) demonstrate that campaigns receive more support when close to its target goal, and less support once the target is reached. Kuppuswamy and Bayus 
(2018) find crowding-out-like effects among backers. They show that many potential backers refrain from participation in a project which already has attracted many backers. Both studies suggest that investors' willingness to invest depends on how impactful the investment appears to be. Hornuf and Schwienbacher (2018) provide support for the theory that investment decisions in equity crowdfunding are partially based on public information on previous investments.

In the context of reward-based crowdfunding, Burtch et al. (2013) and Hong et al. (2015) investigate the total amount contributed to a project on a particular day. They find evidence for partial crowding-out effects, in which an investor's marginal utility decreases when the contribution becomes less important to the recipient. This is consistent with the findings of Kuppuswamy and Bayus (2017, 2018). In addition to the contribution size, Hong et al. (2015) examine the likelihood of a contribution. They find that geographical distance as well as cultural differences affect investment decisions.

\section{Theory and hypotheses development}

In this section, we provide the theoretical background of our study. In particular, we explain the concept behind observational learning in the context of crowdfunding and develop empirically testable hypotheses.

\subsection{Observational learning}

According to Bandura (1977), observational learning occurs by paying attention to others, retaining the information learned, and reproducing the behavior learned from the observed model. The sustainability of this learning process depends largely on motivation.

Observational learning (and information cascades in the financial context) can only take place when decisions are sequential and associated with uncertainty (Bikhchandani et al. 1992). Sequential investment decisions and public observability of investments are typical for equity crowdfunding. Moreover, crowdfunding is often used when the repayment risk appears too high for other investors. Crowdfunding thus serves to transform the risk and size of venture shares. Individual investors may lack both experience and capability in private information acquisition via due diligence to overcome information gaps (Ahlers et al. 2015; Agrawal et al. 2015). However, compared to individuals, markets have superior skills in evaluating projects (Allen and Gale 1999). In the crowdfunding context, this phenomenon can be referred to as the wisdom of crowds, which results from crowd members building up their own decisions based on other members' decisions to end up with better overall decisions (Lévy 1997; Surowiecki 2004; Brabham 2008a, b; Schwienbacher and Larralde 2012). Having this in mind, investors are well advised to observe what decisions were made in the crowd before.

In addition, typically there are no financial reports or analyses offered by analysts or intermediaries because the considered start-up is simply too young. Then, publicly observable investments are even more important to be used as signals. The 
observation of previous investments, in particular their amount, number, and timing, can reduce both the risk and the cost of obtaining information for future investors. Thus, investors can take advantage of the screening efforts of predecessors (Vismara 2018). Ordanini et al. (2011) find that the campaign selection of non-friends-andfamily investors is indeed affected by previous investors' selection. Colombo et al. (2015) show that the number of previous funders as well as how much they pledged positively affect later-stage investors' decisions to invest. When crowdfunders decide to invest on the basis of previous investments, they seem to assume that the predecessors have carried out screening with reliable positive results. Consistent with this, Hornuf and Schwienbacher (2018) find that the number of large investments (5000 $€$ and 10,000 $€$ ) positively affects the number of investments on the following day.

Investment interdependencies are not only information-driven but also payoffdriven. Investors trade stocks at the same time to benefit from a deeper liquidity (Admati and Pfleiderer 1988; Dow 2004). Therefore, the number of players in the game can increase each player's outcome. Transferred to the crowdfunding context, this means that crowdfunders attest hot campaigns a higher probability of success and thus higher expected outcomes. Consequently, they try to benefit by getting involved in the campaign, as they may fear to lose the opportunity of participation in a successful campaign. There is evidence that late investors tend to invest in campaigns which have many previous investments and which are close to their funding goal (Cumming and Johan 2013). Hence, payoff externalities give rise to herding behavior, which means "everyone doing what everyone else is doing" (Banerjee 1992, p. 798). From financial markets research, it is commonly known that herding behavior significantly influences investments (Scharfstein and Stein 1990). It has also been observed in crowdfunding, for example, in online peer-topeer lending (Herzenstein et al. 2018; Lee and Lee 2012; Zhang and Liu 2012), equity crowdfunding (Burtch 2011; Hornuf and Schwienbacher 2018; Moritz et al. 2015; Vulkan et al. 2016; Hornuf and Neuenkirch 2017; Åstebro et al. 2018; Vismara 2018), reward-based crowdfunding (van de Rijt et al. 2014; Colombo et al. 2015; Kim et al. 2015; Zaggl and Block 2019), as well as donation-based (Burtch et al. 2013).

Based on these considerations, we expect to identify interdependencies in investments in our analysis. To address these, we develop testable hypotheses.

\subsection{Hypotheses development}

Recent studies, such as Åstebro et al. (2018), have shown that investor behavior is different when a campaign is more salient and, therefore, considered to be hot. We aim to test for the existence of such an effect on "Companisto" by including a hotness variable. In contrast to Åstebro et al. (2018), our hotness variable is computed solely from publicly observable data on the platform, and not from a potentially non-replicable calculation by the platform or another website, such as Google Trends. The exact computation of this variable will be explained in detail in Sect. 4. We hereby attempt to ensure that statements about the influence of the hotness variable are based on the observation of investments on the platform and not 
driven by external sources or non-replicable computations. We expect investors to invest significantly larger amounts into hot campaigns.

Hypothesis 1 The willingness to pay is larger for hot campaigns.

There are mixed findings concerning the impact of the number of previous investors on investment decisions. On the one hand, a ceteris paribus higher number of investments into the project might be interpreted as positive signal and thus increase the willingness to pay, which can be referred to as "self-fulfilling cascades" (Koning and Model 2014, p. 16,683; see also Colombo et al. 2015; Vismara 2018). In fact, experimental research demonstrates that the public aggregation of online activity and ratings strongly influences others' actions (Muchnik et al. 2013). On the other hand, it is possible that a higher number of funders reduces the benefits resulting from the "crowdfunding experience" (see, e.g., Gerber et al. 2012; Belleflamme et al. 2013, 2014; Belleflamme and Lambert 2014), as the venture is perceived as less exclusive and the investment is perceived to have a lower impact (e.g., Burtch et al. 2013; Hong et al. 2015; Kim et al. 2015; Kuppuswamy and Bayus 2017, 2018). Due to the specific characteristics regarding the investment experience in crowdfunding, we expect to find partial crowding-out effects.

Hypothesis 2 The willingness to pay is negatively related to the number of previous investments.

Moreover, we examine the influence of conspicuously large investments. Experimental research has shown that large contributions have disproportionate impact in terms of encouraging future investments (Koning and Model 2014). Hornuf and Schwienbacher (2018) show that investments of at least $5000 €$ and $10,000 €$ increase the number of investments into a venture on the next day. However, in contrast to them, we investigate the willingness to pay (investment amounts) and do not define large investments by ad-hoc minimum values but rather as relative to the current level of investment amounts. We will explain our definition of conspicuously large investments in Sect. 4. We consider three possible effects of these large investments. First, we include the number of all large investments in the campaign in our regression. We expect a positive effect, as investors are likely to interpret this number as a positive signal regarding the information of other investors.

Hypothesis 3 The willingness to pay is positively related to the number of previous large investments.

Second, we test the impact of the number of large investments into the campaign in the recent past (3 days). In line with observational learning theory, we assume that investors observe previous investments to extract information. Recent investments include information on other investors' beliefs about recent developments concerning venture quality, which are of particular interest for investment decisions. Therefore, we expect that investors put additional weight on recent large investments. 
Hypothesis 4 The willingness to pay is positively related to the number of large investments made during the previous 3 days.

Third, we test whether investment interdependencies are driven by information asymmetries. The crowdfunding literature has revealed a surprising impact of distance on investment probability (see e.g., Agrawal et al. 2015; Lin and Viswanathan 2016), that might be information-driven. Therefore, in contrast to Åstebro et al. (2018), who measure information asymmetries using different investor types (see above), we use a different approach to capture information asymmetries using the geographical distance as a proxy of potential information asymmetries. Geographically proximate investors are likely to have better access to information (e.g., Coval and Moskowitz 1999; Guenther et al. 2018). If investors use large investments to extract information and attribute local investors to have superior information, this number should have an additional positive effect.

Hypothesis 5 The positive impact of recent large investments is larger if the previous investment has been made by a local investor as investors attribute locals to have superior information.

The results of our analysis might be driven by general sentiment, meaning that we find a positive relation between, for example, large investments in the recent past into the campaign and investment amounts, while the effect only occurs because the general sentiment is good. We account for this problem by considering the number of large investments into all other active, that is competing, campaigns instead of the investments into the focal venture itself. If the investment interdependencies are indeed information-driven and not sentiment-driven, large investments in competing campaigns should have no or even a negative impact on the willingness to pay.

Hypothesis 6a The willingness to pay is negatively or not related to the number of large investments in competing campaigns made during the previous 3 days.

Hypothesis $6 \mathbf{b}$ The willingness to pay is negatively or not related to the number of large investments in competing campaigns made by local investors during the previous 3 days.

Hypotheses 1 and 3-5 aim to provide support for whether recent findings also apply to other crowdfunding markets, such as the well-established German equitycrowdfunding platform considered in this study. Hypothesis 2 aims to clarify previously found mixed results. Extending recent research, Hypotheses $6 \mathrm{a}$ and $6 \mathrm{~b}$ aim to provide additional indication that interdependencies between investments are information-driven rather than sentiment-driven.

\section{Empirical setting}

Our analysis is based on data from an equity crowdfunding platform called Companisto. The platform was put into operation in June 2012 in Germany and grows steadily. Companisto uses a typical equity crowdfunding method to connect fundseekers and investors. Participating in a campaign requires a minimum 
investment of $5 €$. Above the minimum, investors can independently choose the amount they want to invest. In return for their investment, investors receive a share in the profits and possible proceeds when the start-up is sold. A special feature of the platform is the two-stage financing system. The first stage of financing covers a period of 2 months maximum to reach the limit threshold of $100,000 €$. If successful, the campaign continues to the second stage, which runs until reaching the target. The campaign ends without extension if it does not pass the limit. In this case, investors are refunded. The financing rounds generally run until the target has been reached.

We hand collected data of all investments $(68,662)$ in the crowdfunding campaigns (101) that have ever been run on Companisto. Our dataset covers the period from August 2012 to January 2019. In the following, the variables used in our analysis are depicted in italics. On the campaign level, Companisto provides information on venture name, location (city and country), Goal type of the campaign (limit vs. target), Goal amount, Co-financing, Equity stake offered, the overall amount invested, percent funded, and the status of the campaign. Based on the venture and campaign description (both text and video) on the platform as well as on the venture websites, we determine the industries according to the SIC classification. The campaigns are from five different industries, where SIC-code $D$ is manufacturing, $F$ is wholesale trade, $G$ is retail trade, $H$ is finance, insurance and real estate, and $I$ is services. On the investor level, the collected data include investor name, location (city and country), Investment amount, and date of investment. Based on this data, we calculate additional timing-related variables, which will be explained in detail in the next section.

Furthermore, using the locations of investors and ventures, we determine latitude and longitude to calculate location-related variables, such as the Distance ${ }^{1}$ between investor and venture, and a dummy variable capturing whether an investor is a Local. In line with Agrawal et al. (2015), we define a local investor as one who lives within a radius of $100 \mathrm{~km}$ from the venture.

We present descriptive statistics for our sample in Table 1.

The mean investment size in our dataset amounts to $641.62 €$. Considering the number of investments $(68,662)$, we have an aggregated investment volume of more than 44 million $€$. Investors deviate from the average investment by a positive amount (additional willingness to pay, $A W P$ ) of approximately $15.41 €$. This additional willingness to pay — which is the dependent variable in our analyses- - has a minimum value of $-2255 €$, and a maximum value of 99,211 $€$. Note that there are three outliers in terms of investment amount (one 100,000 $€$ and two 50,000 $€$ investments), which do not drive our qualitative results. ${ }^{2}$

About $30 \%$ of the campaigns can be assigned to the manufacturing industry $(D)$, while the remaining $70 \%$ are distributed among the industries wholesale trade $(F)$, retail trade $(G)$, finance, insurance and real estate $(H)$, and services $(I)$. Hence, about $30 \%$ of the ventures offer physical products, while others do not. About half of the

\footnotetext{
${ }^{1}$ We calculate the distance using the reference ellipsoid from the World Geodetic System 1984 (see, e.g., Kumar 1988).

2 Our qualitative results are robust to winsorizing or truncating.
} 
Table 1 Descriptive statistics

\begin{tabular}{|c|c|c|c|c|}
\hline Variables & Mean & SD & Min & Max \\
\hline Additional willingness to pay (AWP) & 15.41 & 1679.46 & -2255.03 & $99,211.16$ \\
\hline Investment amount & 641.62 & 1701.60 & 5.00 & $100,000.00$ \\
\hline Mean investment & 626.21 & 261.21 & 116.85 & 2355.03 \\
\hline Hot campaign & 0.55 & 0.50 & 0.00 & 1.00 \\
\hline \# Previous investments & 436.09 & 387.36 & 0.00 & 2273.00 \\
\hline \# Large investments & 31.88 & 36.61 & 0.00 & 377.00 \\
\hline \# Large investments previous 3 days & 3.39 & 5.93 & 0.00 & 45.00 \\
\hline \# Large investments previous 3 days by locals & 0.62 & 1.52 & 0.00 & 14.00 \\
\hline \# Large investments previous 3 days (platform) & 7.51 & 7.41 & 0.00 & 45.00 \\
\hline $\begin{array}{l}\text { \# Large investments previous } 3 \text { days by locals } \\
\text { (platform) }\end{array}$ & 1.31 & 2.00 & 0.00 & 14.00 \\
\hline \# Large investments (platform) & 1718.49 & 1331.79 & 0.00 & 5919.00 \\
\hline$D$ & 0.30 & 0.46 & 0.00 & 1.00 \\
\hline$F$ & 0.01 & 0.10 & 0.00 & 1.00 \\
\hline$G$ & 0.18 & 0.38 & 0.00 & 1.00 \\
\hline$H$ & 0.01 & 0.12 & 0.00 & 1.00 \\
\hline$I$ & 0.50 & 0.50 & 0.00 & 1.00 \\
\hline Campaign Berlin & 0.48 & 0.50 & 0.00 & 1.00 \\
\hline Goal type & 0.69 & 0.46 & 0.00 & 1.00 \\
\hline Goal amount & $825,377.87$ & $873,979.25$ & $50,000.00$ & $5500,000.00$ \\
\hline Co-financing & 0.07 & 0.25 & 0.00 & 1.00 \\
\hline Equity stake offered & 12.67 & 7.78 & 2.44 & 37.50 \\
\hline Project day count & 60.68 & 144.82 & 1.00 & 1982.00 \\
\hline Sniping & 0.11 & 0.32 & 0.00 & 1.00 \\
\hline Distance & 421.30 & 759.28 & 0.00 & $18,676.30$ \\
\hline Local & 0.13 & 0.34 & 0.00 & 1.00 \\
\hline Friends and family & 0.18 & 0.38 & 0.00 & 1.00 \\
\hline \# Start-ups before & 8.37 & 12.55 & 0.00 & 91.00 \\
\hline
\end{tabular}

Observations: 68,662

ventures is located in Berlin. 7\% of all campaigns received Co-financing before or parallel to crowdfunding.

Approximately 680 investments are made per campaign, with the average number of investments before the investment under consideration (\# Previous investments) being 436. At the time of investment, investors have previously supported a mean number of 8.4 start-ups (\# Start-ups before). On campaign level, there have been, on average, 32 large investments (\# Large investments) before, of which 3.4 investments were made within the past 3 days (\# Large investments previous 3 days). Locals are responsible for less than one (0.6) of these large 
investments (\# Large investments previous 3 days by locals). About 55\% of all investments are made in hot campaigns (Hot campaign), which emphasizes the importance to consider such a variable in the analysis.

\section{Econometric model}

We examine the factors that cause investors to deviate from the average investment amount at the time of the investment. We do not use the investment amount as dependent variable, as its mean steadily increases over time. Instead, we calculate the average amount invested per investment on the platform over the last 28 days for each investment (Mean investment). We use this value as estimate of the usual level of investment amounts at the time of the investment. The chosen number of days for the estimation represents a compromise: on the one hand, this ensures sufficient estimation precision, while on the other hand, the average investment amounts within 28 days do not vary too much. The difference between the amount invested and the usual level of investment amount, which we will hereinafter refer to as the additional willingness to pay $(A W P)$, is our dependent variable:

$$
\mathrm{AWP} \equiv \text { Investment amount - Mean investment. }
$$

This variable is of interest to practitioners and researchers, as it reflects whether and to what extent individual investors deviate from typical investment behavior. This allows us to identify the drivers of investment amounts after controlling for purely time-related factors.

Furthermore, this variable is well suited for the statistical analysis, as it appears to be relatively stationary. To account for the fact that we have time-series data, we adjust standard errors using the method of Newey and West (1987). This addresses the remaining possibility of heteroskedasticity and autocorrelation.

In line with Åstebro et al. (2018), we use a linear regression. In addition, we include investor fixed effects. These fixed effects are intended to capture unobservable investor characteristics, such as wealth or the general willingness to pay. As controls, we consider various variables that could have an influence on crowdfunding decisions. On the campaign level these are the type of industry (dummy variables: manufacturing $D$; Finance, Insurance, And Real Estate $H$; Services I; the reference group is Trade $F+G$ ), Goal type and Goal amount, a dummy variable indicating whether more than $90 \%$ of the goal amount are reached (Sniping), the Equity stake offered, a dummy that indicates if the venture has been co-financed (Co-financing), a dummy indicating if the venture is located in Berlin (Campaign Berlin) and the number of days a campaign has already been available on Companisto (Project day count).

On the investor level, we control for the Distance between investor and venture, the number of start-ups an investor has invested in before (\# Start-ups before), and we include a dummy variable indicating if an investor has to be considered Friends and family. Note that we adopt the criteria of Agrawal et al. (2015) for Friends and family of a venture: (1) they invest in the focal start-up before investing in any other start-up, (2) that investment is the largest of their investments on the website, and 
(3) they invest in no more than three other campaigns. This variable is of particular importance, as Agrawal et al. (2015) show that these investors behave completely differently in terms of investment probabilities. It can, therefore, be assumed that Friends and family must also be considered separately with regard to the invested amounts. Since it is particularly interesting for entrepreneurs to understand the decisions of investors outside their private network, all analyses are also carried out excluding the observations of investments of Friends and family, which account for $17.5 \%$ of all investments.

The main research question revolves around the interdependencies between investments with a focus on conspicuous previous investments. To test for these, we include the following variables in our regression.

Addressing Hypothesis 1, we compute a dummy variable Hot campaign, which indicates whether a campaign is the most popular campaign on the platform at the time of investment. It is one if the campaign has the highest number of investments in the last 3 days of all active campaigns and the number of investments into the campaign in the last 3 days exceeds the mean number of investments in a campaign in 3 days over the whole sample. The latter condition makes sure that the campaign is not only the most popular campaign at the particular day but also popular in comparison to all other days.

Furthermore, we include the number of investments into the project prior to the investment under consideration (\# Previous investments, Hypothesis 2).

Moreover, we examine the influence of conspicuously large investments. In particular, we compute the mean and standard deviation of investment amounts in the last 28 days. All investments, which exceed the mean amount plus a standard deviation, are considered as conspicuously large. We checked the robustness of our qualitative results by altering the number of standard deviations.

Recall that we consider three possible effects of these large investments. First, we include the number of all large investments in the campaign (\# Large investments) in our regression (Hypothesis 3). Furthermore, we include the number of large investments in the recent past (\# Large investments previous 3 days) into the campaign (Hypothesis 4). Specifically, we consider 3 days in our main model. We also tested the model considering 5 and 7 days to check for robustness. As the crowdfunding literature has revealed a surprising impact of distance on investment probability (see, e.g., Agrawal et al. 2015), that might be information-driven, we include the number of large investments of local investors (\# Large investments previous 3 days by locals), who are located less than $100 \mathrm{~km}$ from the venture, in the recent past (Hypothesis 5). This aims to capture whether investors attribute locals to have superior information.

Thus, the regression formula is specified as follows (a summary of variable definitions is given in Table 2): 
Table 2 List of variables

\begin{tabular}{|c|c|}
\hline Variable names & Description \\
\hline $\begin{array}{l}\text { Additional willingness to pay } \\
\qquad(A W P)\end{array}$ & $\begin{array}{l}\text { Dependent variable; difference between investment amount and mean } \\
\text { investment at the time of investment }\end{array}$ \\
\hline Investment amount & Volume of the investment considered \\
\hline Mean investment & $\begin{array}{l}\text { Mean of investments made in the campaign before the investment } \\
\text { considered }\end{array}$ \\
\hline Hot campaign & $\begin{array}{l}\text { Equals } 1 \text { if the considered campaign has the highest number of } \\
\text { investments in the last } 3 \text { days of all active campaigns and the } \\
\text { number of investments into the campaign in the last } 3 \text { days exceeds } \\
\text { the mean number of investments in a campaign in } 3 \text { days over the } \\
\text { whole sample; } 0 \text { otherwise }\end{array}$ \\
\hline \# Previous investments & Number of all previous investments in the considered campaign \\
\hline \# Large investments & Number of large investments in the considered campaign \\
\hline $\begin{array}{l}\text { \# Large investments previous } \\
3 \text { days }\end{array}$ & $\begin{array}{l}\text { Number of large investments in the considered campaign during the } \\
\text { previous } 3 \text { days }\end{array}$ \\
\hline $\begin{array}{l}\text { \# Large investments previous } \\
3 \text { days by locals }\end{array}$ & $\begin{array}{l}\text { Number of large investments by locals in the considered campaign } \\
\text { during the past } 3 \text { days }\end{array}$ \\
\hline$D, F, G, H, I$ & $\begin{array}{l}\text { Equals } 1 \text { if the SIC-code for the venture's industry is } \mathrm{D}, \mathrm{F}, \mathrm{G}, \mathrm{H} \text { or I } \\
\text { respectively; } 0 \text { otherwise }\end{array}$ \\
\hline Campaign Berlin & Equals 1 if the venture's location is Berlin \\
\hline Goal $t$ & $\begin{array}{l}\text { Equals } 1 \text { if the campaign's goal type is "target"; } 0 \text { if the goal type is } \\
\text { "limit" }\end{array}$ \\
\hline Goal amount & Requested amount of capital by the venture \\
\hline Co-financing & Equals 1 if the campaign has been co-financed; 0 otherwise \\
\hline Equity stake offered & Percentage of Equity offered \\
\hline Project day count & $\begin{array}{l}\text { The number of days a campaign has been available on Companisto by } \\
\text { the day considered }\end{array}$ \\
\hline Sniping & Equals 1 if more than $90 \%$ of the goal amount are reached; 0 otherwise \\
\hline Distance & Distance between investor and venture in kilometers \\
\hline Local & $\begin{array}{l}\text { Equals } 1 \text { if investor location is not more than } 100 \mathrm{~km} \text { away from the } \\
\text { venture; } 0 \text { otherwise }\end{array}$ \\
\hline Friends and family & $\begin{array}{l}\text { Equals } 1 \text { if an investor is a friend or family member using the method } \\
\text { described in Agrawal et al. (2015); } 0 \text { otherwise }\end{array}$ \\
\hline \# Start-ups before & Number of start-ups an investor has invested before \\
\hline
\end{tabular}

AWP $=\beta_{1} \cdot$ Hot campaign $+\beta_{2} \cdot \#$ Previous investments

$+\beta_{3} \cdot \#$ Large investments

$+\beta_{4} \cdot \#$ Large investments previous three days

$+\beta_{5} \cdot \#$ Large investments previous three days by locals

+ Controls + Fixed effects + Error terms.

The results of our analysis might be driven by general sentiment. We account for this problem by running the above regression again considering the number of large 
investments into all other active campaigns instead of the investments into the focal venture itself (Hypothesis 6a, 6b). If the computed effects from the first regression are indeed information-driven and not sentiment-driven, these numbers of large investments should have no or even a negative impact on the willingness to pay. Note that a simultaneous inclusion of the number of investments into the venture and into competing campaigns is not feasible, as the variance inflation factors become too high, leading to unsuitable standard errors.

\section{Results and discussion}

In this section, we present our results. Table 3 depicts the regression's coefficients with standard errors and the variance inflation factors (VIFs).

Satisfying the most common rules of thumb with respect to multicollinearity, for example, the "rule of 10", all of our variables' VIFs are below 5. Note that most of our main results are statistically significant. Therefore, multicollinearity is not a problem in our analysis (for a technical explanation, see O'Brien 2007). In the next parts of this section, we discuss the plausibility of our controls' coefficients.

Table 3 Regression results main model

\begin{tabular}{|c|c|c|c|c|}
\hline Variables & Estimate & Std. error & $t$ value & VIF \\
\hline \multicolumn{5}{|c|}{ Dependent variable: Additional willingness to pay (AWP) } \\
\hline \multicolumn{5}{|l|}{ Model: Linear regression with investor fixed effects } \\
\hline Hot campaign & $65.54 * * *$ & 12.1 & 5.43 & 1.31 \\
\hline \# Previous investments & $-0.21 * * *$ & 0.033 & -6.51 & 4.12 \\
\hline \# Large investments & $2.85 * * *$ & 0.386 & 7.38 & 4.40 \\
\hline \# Large investments previous 3 days & $4.16^{* *}$ & 1.61 & 2.59 & 3.71 \\
\hline \# Large investments previous 3 days by locals & 1.55 & 6.64 & 0.233 & 3.46 \\
\hline$D$ & $65.09 * * *$ & 18.8 & 3.47 & 2.17 \\
\hline$H$ & 9.97 & 46.3 & 0.215 & 1.10 \\
\hline$I$ & -18.12 & 15.5 & -1.17 & 1.94 \\
\hline Campaign Berlin & 1.03 & 11.6 & 0.088 & 1.13 \\
\hline Goal type & $85.23 * * *$ & 15.4 & 5.54 & 1.38 \\
\hline Goal amount & $6.55 \mathrm{E}-05^{* * *}$ & $1.39 \mathrm{E}-05$ & 4.72 & 1.75 \\
\hline Co-financing & -57.50 & 33.1 & -1.74 & 1.48 \\
\hline Equity stake offered & 1.51 & 0.954 & 1.58 & 1.33 \\
\hline Project day count & $-0.13 * * *$ & 0.04 & -3.34 & 1.21 \\
\hline Sniping & -26.59 & 20.7 & v1.28 & 1.47 \\
\hline Distance & $-0.12 * *$ & 0.040 & -3.04 & 1.01 \\
\hline Friends and family & $486.68 * * *$ & 18.5 & 26.2 & 1.12 \\
\hline \# Start-ups before & $-4.44 * * *$ & 0.712 & -6.24 & 1.14 \\
\hline Observations: 68,$662 ;$ Adj. $R$ squared: 0.5847 & \multicolumn{4}{|c|}{$* * * p<0.001, * * p<0.01, * p<0.05$} \\
\hline
\end{tabular}




\subsection{Control variables}

We start with variables that have been subject of other empirical studies on crowdfunding. Previous research has shown that geographically proximate investors are more likely to invest into a venture (Agrawal et al. 2015; Lin and Viswanathan 2016; Guenther et al. 2018). This phenomenon is commonly known as home bias or local bias. Therefore, we include the distance between investor and venture in our regression. We find a statistically and economically significant negative effect on willingness to pay off about $12 €$ per $100 \mathrm{~km}$. This suggests that, in line with previous research, there is local bias on the platform considered. Moreover, given that information asymmetries may increase with distance, this result further suggests that greater information asymmetries discourage investments.

Furthermore, we control for the venture being located in Berlin. An effect on the willingness to pay might occur because Berlin is one of Europe's most popular cities for start-ups (e.g., Gough 2017; Ernst and Young 2018; Monteiro 2018), and 47\% of ventures in our sample are located there. However, we find no significant effect, indicating that no such effect exists in our sample.

The phase of investment has an impact. If a campaign's goal type is target (second stage of funding), that is Goal type equals 1 , the $A W P$ is about $85 €$ higher. This can be explained by the positive signal of the campaign having already passed the limit threshold of $100,000 €$ (first stage of funding).

Interestingly, the demanded amount of financing (Goal amount) has a positive effect on $A W P$. If the goal amount ceteris paribus increases by $10,000 €, A W P$ on average increases by about $6.55 €$. This result might be explained by warm-glow giving, which is a form of altruism and describes funders' motivation to give money to generate self-esteem benefits. While purely altruistic funders may be subject to free-riding and crowding-out issues, warm glow explains why crowding-out as described above is no absolute phenomenon (Gleasure and Feller 2013). Therefore, warm glow may be the reason why individuals tend to give more to people in need. In our context, this translates to investors choosing higher investments amounts when ventures have higher financial needs.

We further find that the Equity stake offered has a positive effect on $A W P$, which is insignificant at the 5\% level. In particular, a one percentage-point increase in the offered equity stake is associated with an increase of the additional willingness to pay by $1.51 €$. Investors may regard a higher percentage of equity being offered to the crowd as a positive signal of trust by the venture. Investors may perceive the impact of the crowd on the venture and its entrepreneurs as greater. This eventually translates into a better crowdfunding experience, and thus encourages investments.

Sniping, that is late bidding, is a phenomenon that has been detected on Internet auctions (Ariely et al. 2005). Companisto has no auction but a "first-come-firstserve" mechanism. However, it is conceivable that this phenomenon also appears on the crowdfunding website under consideration, as there is a fixed end time for each campaign, regardless of whether it is a limit or target campaign. In our sample, the coefficient is not significant, meaning that no sniping occurs.

A further time-related control is the number of days a campaign has been available (Project day count). We find a negative effect, which is in line the 
L-shaped investment pattern in equity crowdfunding identified by Hornuf and Schwienbacher (2018).

Importantly, in contrast to related studies, such as Åstebro et al. (2018), and Hornuf and Schwienbacher (2018), we control for Friends and family. We do this in two ways. First, we include a dummy variable and second we run a separate regression excluding all observations, for which this dummy equals one. Agrawal et al. (2015) find that friends and family behave differently regarding investment probability. We find that these investors also choose substantially higher additional investment amounts. In particular, friends and family have an $A W P$ that is on average close to $500 €$ higher than the one of other investors, which is economically significant.

Our analysis also features controls to which less attention has been paid so far. One is the industry type. We find that the $A W P$ in ventures of industry $D$, that is manufacturing, is ceteris paribus about $65 €$ higher than the $A W P$ of other industries. The willingness to pay might be increased by the crowdfunding experience. This effect might be stronger the better investors can identify with the venture or its products. Ventures classified as manufacturing feature tangible products, whereas other industries, such as trade/commerce or finance, produce nothing directly tangible.

We further control for the number of start-ups an investor has invested in prior to the investment considered (\# Start-ups before). We find a significantly negative effect of $4.44 €$ per start-up. If investors had a fixed budget, the amount invested would be smaller if it were distributed over many start-ups. A more sophisticated explanation is that investors, who invest into many start-ups, most likely do so primarily because they want to diversify and not because they want to support every single entrepreneur. Therefore, the crowdfunding experience and, in turn, the additional willingness to pay might be lower than for those investors who only invest in a small number of start-ups.

\subsection{The impact of previous investments}

We now turn to the main research question-the interdependencies between investments. We find that if the focal campaign is hot, meaning that it currently is the most popular campaign on the platform, $A W P$ is about $66 €$ higher. This supports Hypothesis 1. A possible explanation for investors to invest significantly more into hot campaigns might be of psychological nature, meaning that the campaign, which is the most popular at the time of investment, is perceived to be more attractive. Another possible explanation is that investors may attest hot campaigns a higher probability of success and thus higher expected outcomes. This may encourage investments in the focal campaign. A third explanation relates to informational effects and is consistent with observational learning theory. Investors may learn by observing previous investments. Strong information externalities or conspicuously high numbers of recent investments may be understood as a particularly positive signal about venture quality. This may further encourage investments in hot campaigns. 
Furthermore, we consider conspicuously large investments. We find a positive effect on $A W P$, both for the total number of large investments in the campaign and the number of large investments in the past few days ( 3 days in our main model). This supports Hypotheses 3 and 4, and suggests that investors indeed use large investments as a signal for favorable information from other investors. The total number of investments reflects more general information, while recent investments might be used to extract up-to-date information on, for example, the particular market a venture is addressing. Both effects are statistically significant and amount to around $3 €$ per large investment before and an additional $4 €$ per large investments in the previous 3 days. These results are consistent with previous research stating that crowd investors are prone to rational herding (e.g., Herzenstein et al. 2018; Lee and Lee 2012; Zhang and Liu 2012; Hornuf and Schwienbacher 2018; Vismara 2018; Åstebro et al. 2018; Cong and Xiao 2018).

Recent literature has shown that distance plays a role when it comes to crowdfunding decisions. As these could be information-driven, investors might attribute locals to have better up-to-date information because of superior access. Therefore, we include the number of local investments in the past few days. However, we find no significant effect, meaning that investors most likely do not distinguish between local and non-local investments. Therefore, we find no support for Hypothesis 5.

The qualitative results are robust to changing the number of days considered for investments in the recent past to 5 or 7 days, and altering the number of standard deviations used to compute the number of large investments. Furthermore, the results are robust to excluding Friends and family, which is shown in "Appendix" (see Table 5). ${ }^{3}$

Regarding the existence of co-financing before or parallel to the campaign, we find a ceteris paribus negative effect, which, at first glance is surprising. Note that this effect has a $p$ value of $8 \%$. Sophisticated investors, such as venture capitalists or business angels, have more experience and typically invest larger amounts of capital. These investors are intensively involved in the acquisition of information (for example, screening, due diligence, contact with entrepreneurs). If a venture receives co-financing, this can be regarded as a positive signal to the crowd. However, as the existence of a co-financier negatively influences the additional willingness to pay in our data, there must be another reason that outweighs the described mechanism. One possible explanation is a reduction in the crowdfunding experience of supporting the entrepreneurs. If a start-up already receives funding elsewhere, the impact of every single crowd investment is smaller. This may reduce the additional utility investors derive from the crowdfunding experience. The partial crowding-out effect is consistent with previous findings (e.g., Kuppuswamy and Bayus 2017, 2018; Burtch et al. 2013; Hong et al. 2015).

We find yet another indication for the crowding-out effect. That is, the total number of investments into the campaign (\# Previous investments) has a negative effect on $A W P$. This supports Hypothesis 2. The value of $-0.21 €$ per previous

\footnotetext{
${ }_{3}^{3}$ Recall that our results are also robust to winsorizing or truncating, meaning that it is unlikely that the results are driven by outliers.
} 
investment seems to be low. However, as the mean of \# Previous investments in our sample amounts to 436, the effect is on average greater than $90 €$, which is economically significant. Investors might perceive a venture with many other investors as less exclusive and they might think that their investment has less impact. Both reduce the benefits from pure altruism and the crowdfunding experience, and thereby the willingness to pay. This finding is in line with Kim et al. (2015) who also find a crowding-out effect from the number of investors in rewardbased crowdfunding.

\subsection{Information vs. sentiment}

Overall, the regression results presented in the previous section provide the indication of information-driven interdependencies between investments. To check that the results are not solely explained by sentiment, we run our regression once again. However, instead of the number of large investments in the recent past, we now include the number of large investments in competing campaigns. If sentiment was the driver of our results, we would expect to observe the same direction of effects, whereas there should be no or even reversed effects, when the effects on $A W P$ were driven by information. The results of our second regression are presented in Table 4.

It is evident that all qualitative effects other than the number of large investments remain unchanged. For the number of large investments into competing campaigns we find a negative effect for all investors and an insignificant effect for locals. This supports Hypothesis $6 \mathrm{a}$ and suggests that the results of our previous regression regarding large investments are indeed information-driven and investors use previous large investments to extract information. Furthermore, this finding supports our explanation for the effect of hot campaigns. It seems like investors decide how much to invest in a campaign by comparing it to other active campaigns. If another campaign has attracted lots of large investments, the campaign the investor considers appears less attractive to her, which might decrease her willingness to pay. We find no support for Hypothesis $6 b$.

\section{Concluding remarks}

It is a central function of crowdfunding to raise capital. Once investors have decided to participate, entrepreneurs hope for high investments. Understanding what motivates funders to invest more is important for both entrepreneurs and platforms. The business model of crowdfunding platforms is based on the successful connection of entrepreneurs and investors. Entrepreneurs typically seek maximum proceeds from crowdfunding. Aiming to contribute to research on investment behavior in equity crowdfunding, this paper empirically investigates what causes deviations from typical investment behavior, and what role conspicuous investment behavior of other investors plays.

We find that investors are willing to invest more into hot campaigns. Furthermore, investors tend to contribute more if there have been many large 
Table 4 Regression results on platform level

\begin{tabular}{lllrr}
\hline Variables & Estimate & Std. error & $t$ value & VIF \\
\hline Dependent variable: Additional willingness to pay $(A W P)$ & & & \\
Model: Linear regression with investor fixed effects & & & & \\
Hot campaign & $66.84^{* * *}$ & 12.2 & 5.48 & 1.33 \\
\# Previous investments & $-0.23^{* * *}$ & 0.033 & -6.94 & 4.08 \\
\# Large investments & $3.09^{* * *}$ & 0.385 & 8.02 & 4.30 \\
\# Large investments previous 3 days & $-6.12^{* * *}$ & 1.26 & -4.85 & 2.53 \\
\# Large investments previous 3 days by locals & 9.23 & 4.83 & 1.91 & 2.28 \\
D & $59.84^{* *}$ & 18.7 & 3.2 & 2.17 \\
H & -4.45 & 46.2 & -0.097 & 1.10 \\
I & -22.94 & 15.5 & -1.48 & 1.94 \\
Campaign Berlin & 0.24 & 11.7 & 0.020 & 1.13 \\
Goal type & $88.38^{* * *}$ & 15.6 & 5.68 & 1.37 \\
Goal amount & $6.73 \mathrm{E}-05^{* * *}$ & $1.39 \mathrm{E}-05$ & 4.84 & 1.72 \\
Co-financing & -64.19 & 33.1 & -1.94 & 1.47 \\
Equity stake offered & 1.54 & 0.957 & 1.61 & 1.33 \\
Project day count & $-0.13^{* *}$ & 0.040 & -3.27 & 1.22 \\
Sniping & -30.74 & 20.6 & -1.49 & 1.47 \\
Distance & $-0.12^{* *}$ & 0.040 & -3.09 & 1.01 \\
Friends and family & $482.30^{* * *}$ & 18.5 & 26 & 1.12 \\
\# Start-ups before & $-4.15^{* * *}$ & 0.712 & -5.83 & 1.14 \\
Observations: 68,662; Adj. $R$ squared: 0.5846 & $* * * p<0.001, * * p<0.01, * p<0.05$ & \\
\hline
\end{tabular}

investments before, which suggests that they observe previous investments, and use (recent) large investments as signals of favorable information of other investors. Consistent with previous research, our findings support the theory of observational learning by investors. The differences in the analysis at platform level confirm the assumption that investor behavior is indeed information-driven and not purely sentiment-driven. In addition, we find indication that investors in crowdfunding are subject to partial crowding-out. This finding is based on two results of our analysis. First, the existence of a presumably sophisticated co-financier has a negative impact on investments. Second, a high number of all previous investments negatively influences investments.

Our study contributes to the literature by considering a dependent variable, which is of interest to practitioners and researchers, as it reflects whether and to what extent individual investors deviate from typical investment behavior. This allows for identifying the drivers of investment amounts after controlling for purely timerelated factors. Another contribution is the consideration of a comprehensive set of control variables including industry dummies, a friends-and-family dummy, and geographical distance. Second, by considering the impact of investments in competing campaigns, we provide additional indication that investment interdependencies are rather information-driven than sentiment-driven. This further 
suggests that investors compare active campaigns when determining their willingness to pay.

Acknowledgements We thank the editor (Thomas Gehrig) for handling our manuscript and the anonymous referee for constructive comments that significantly improved the paper.

Open Access This article is licensed under a Creative Commons Attribution 4.0 International License, which permits use, sharing, adaptation, distribution and reproduction in any medium or format, as long as you give appropriate credit to the original author(s) and the source, provide a link to the Creative Commons licence, and indicate if changes were made. The images or other third party material in this article are included in the article's Creative Commons licence, unless indicated otherwise in a credit line to the material. If material is not included in the article's Creative Commons licence and your intended use is not permitted by statutory regulation or exceeds the permitted use, you will need to obtain permission directly from the copyright holder. To view a copy of this licence, visit http:// creativecommons.org/licenses/by/4.0/.

\section{Appendix}

See Table 5.

Table 5 Regression results model without friends and family

\begin{tabular}{lllll}
\hline Variables & Estimate & Std. error & $t$ value & VIF \\
\hline Dependent variable: Additional willingness to pay & $(A W P)$ & & & \\
Model: Linear regression with investor fixed effects & & & & \\
Hot campaign & $66.31^{* * *}$ & 13.1 & 5.08 & 1.31 \\
\# Previous investments & $-0.22^{* * *}$ & 0.036 & -6.1 & 4.06 \\
\# Large investments & $2.91^{* * *}$ & 0.424 & 6.85 & 4.34 \\
\# Large investments previous 3 days & $4.18^{*}$ & 1.66 & 2.51 & 3.75 \\
\# Large investments previous 3 days by locals & 2.40 & 6.93 & 0.346 & 3.51 \\
D & $69.59^{* * *}$ & 20 & 3.48 & 2.12 \\
H & 17.40 & 48.9 & 0.355 & 1.10 \\
I & -14.69 & 16.5 & -0.89 & 1.92 \\
Campaign Berlin & -3.18 & 12.5 & -0.255 & 1.13 \\
Goal type & $90.58^{* * *}$ & 16.4 & 5.52 & 1.37 \\
Goal amount & $7.45 \mathrm{E}-05^{* * *}$ & $1.47 \mathrm{E}-05$ & 5.08 & 1.71 \\
Co-financing & -64.88 & 36.2 & -1.79 & 1.47 \\
Equity stake offered & 1.24 & 1.04 & 1.19 & 1.30 \\
Project day count & $-0.14 * *$ & 0.046 & -3.12 & 1.21 \\
Sniping & -3.01 & 22.2 & -1.35 & 1.48 \\
Distance & $-0.12^{* *}$ & 0.044 & -2.68 & 1.00 \\
\# Start-ups before & $-4.58^{* * *}$ & 0.719 & -6.38 & 1.04 \\
Observations: 56,622; Adj. $R$ squared: 0.4094 & $* * * p<0.001, * * p<0.01, * p<0.05$ & \\
\hline & & & & \\
\hline
\end{tabular}




\section{References}

Åstebro, T.B., S. Lovo, M. Fernandez Sierra, and N. Vulkan. 2018. Herding in Equity Crowdfunding. HEC Research Papers Series 1245, HEC Paris.

Admati, A.R., and P. Pfleiderer. 1988. A Theory of Intraday Patterns: Volume and Price Variability. The Review of Financial Studies 1: 3-40.

Agrawal, A., C. Catalini, and A. Goldfarb. 2015. Crowdfunding: Geography, Social Networks, and the Timing of Investment Decisions. Journal of Economics and Management Strategy 24: 253-274.

Ahlers, G.K.C., D. Cumming, C. Günther, and D. Schweizer. 2015. Signaling in Equity Crowdfunding. Entrepreneurship Theory and Practice 39: 955-980.

Allen, F., and D. Gale. 1999. Diversity of opinion and financing of new technologies. Journal of Financial Intermediation 8: 68-89.

Ariely, D., A. Ockenfels, and A.E. Roth. 2005. An experimental analysis of ending rules in Internet auctions. RAND Journal of Economics 36: 891-908.

Babich, V., S. Marinesi, and G. Tsoukalas. 2018. Does Crowdfunding Benefit Entrepreneurs and Venture Capital Investors? Georgetown McDonough School of Business Research No. 2971685; The Wharton School Research Paper, http://dx.doi.org/10.2139/ssrn.2971685.

Bandura, A. 1977. Social Learning Theory. New Jersey: Pentice Hall.

Banerjee, A.V. 1992. A Simple Model of Herd Behavior. The Quarterly Journal of Economics 107: 797-817.

Belleflamme, P., and T. Lambert. 2014. Crowdfunding: Some Empirical Findings and Microeconomic Underpinnings. SSRN Working Paper, http://dx.doi.org/10.2139/ssrn.2437786.

Belleflamme, P., T. Lambert, and A. Schwienbacher. 2013. Individual Crowdfunding Practices. Venture Capital 15: 313-333.

Belleflamme, P., T. Lambert, and A. Schwienbacher. 2014. Crowdfunding: Tapping the right crowd. Journal of Business Venturing 29: 585-609.

Bi, S., Z. Liu, and K. Usman. 2017. The influence of online information on investing decisions of rewardbased crowdfunding. Journal of Business Research 71: 10-18.

Bikhchandani, S., D. Hirshleifer, and I. Welch. 1992. A Theory of Fads, Fashion, Custom, and Cultural Change as Informational Cascades. Journal of Political Economy 100: 992-1026.

Brabham, D.C. 2008a. Crowdsourcing as a Model for Problem Solving: An Introduction and Cases. Convergence: The International Journal of Research into New Media Technologies 14: 75-90.

Brabham, D.C. 2008b. Moving the Crowd at iStockphoto: The Composition of the Crowd and Motivations for Participation in a Crowdsourcing Application. First Monday 13, https://www. firstmonday.dk/ojs/index.php/fm/article/view/2159/1969. Accessed 26 June 2019.

Bursztyn, L., F. Ederer, B. Ferman, and N. Yuchtman. 2014. Understanding Mechanisms Underlying Peer Effects: Evidence From a Field Experiment on Financial Decisions. Econometrica 82: 1273-1301.

Burtch, G., 2011. Herding behavior as a network externality. In: Thirty Second International Conference Information Systems (Shanghai).

Burtch, G., A. Ghose, and S. Wattal. 2013. An Empirical Examination of the Antecedents and Consequences of Investment Patterns in Crowd-Funded Markets. Information Systems Research 24: 499-519.

Chapman, G.B., and E.J. Johnson. 2002. The psychology of intuitive judgment. In Heuristics and Biases, ed. T. Gilovich, D. Griffin, and D. Kahneman. Cambridge: Cambridge University Press.

Colombo, M.G., C. Franzoni, and C. Rossi-Lamastra. 2015. Internal Social Capital and the Attraction of Early Contributions in Crowdfunding. Entrepreneurship Theory and Practice 39: 75-100.

Cong, L.W., and Y. Xiao. 2018. Up-cascaded wisdom of the crowd. Unpublished Working Paper. https:// financetheory.org/wp-content/uploads/gravity_forms/1-70ba24ead09917a027e3e47d3324b973/ 2018/02/UCWC-Cong-Xiao-2018.pdf. Accessed 15 Oct 2019.

Coval, J.D., and T.J. Moskowitz. 1999. Home Bias at Home: Local Equity Preference in Domestic Portfolios. The Journal of Finance 54: 2045-2073.

Cumming, D., and S.A. Johan. 2013. Venture Capital and Private Equity Contracting. Amsterdam: Elsevier.

Dow, J. 2004. Is Liquidity Self-Fulfilling? The Journal of Business 77: 895-908.

Ernst \& Young. 2018. Fast growth in Germany-Tech start-ups and investors setting new benchmarksVenture Capital and start-ups in Germany 2017. https://www.ey.com/Publication/vwLUAssets/eyfast-growth-in-germany/\$FILE/ey-fast-growth-in-germany.pdf. Accessed 24 June 2019. 
Gerber, E.M., and J.S. Hui. 2013. Crowdfunding: Motivations and Deterrents for Participation. ACM Transactions on Computer-Human Interaction 20: 34:1-34:32.

Gerber, E.M., J.S. Hui, and P.Y. Kuo. 2012. Crowdfunding: Why People are Motivated to Post and Fund Projects on Crowdfunding Platforms. https://pdfs.semanticscholar.org/c1e2/ a1068f0af1c3120c62be5943340518860ecb.pdf. Accessed 1 June 2019.

Gleasure, R., and J. Feller. 2013. Does Heart or Head Rule Donor Behaviors in Charitable Crowdfunding Markets? International Journal of Electronic Commerce 20: 499-524.

Gough, O. 2017. London start-ups lag behind Berlin, Paris and Dublin post-Brexit vote. https:// smallbusiness.co.uk/london-start-ups-behind-berlin-2537846/. Accessed 24 Apr 2019.

Guenther, C., S. Johan, and D. Schweizer. 2018. Is the crowd sensitive to distance?-how investment decisions differ by investor type. Small Business Economics 50: 289-305.

Herzenstein, M., C. Guenther, S. Johan, and D. Schweizer. 2018. Is the crowd sensitive to distance?how investment decisions differ by investor type. Small Business Economics 50: 289-305.

Hong, Y., Y. Hu, and G. Burtch. 2015. How does Social Media AffectContribution to Public versus Private Goods in Crowdfunding Campaigns? International Conference on Information Systems: Exploring the Information Frontier, Fort Worth, US.

Hornuf, L., and M. Neuenkirch. 2017. Pricing shares in equity crowdfunding. Small Business Economics 48: 795-811.

Hornuf, L., and A. Schwienbacher. 2018. Market mechanisms and funding dynamics in equity crowdfunding. Journal of Corporate Finance 50: 556-574.

Kim, J.-H., P. Newberry, and C. Qiu. 2015. An Empirical Analysis of a Crowdfunding Platform. NET Institute Working Paper No. 15-12, http://dx.doi.org/10.2139/ssrn.2672075.

Koning, R., and J. Model. 2014. Experimental Study of Crowdfunding Cascades: When Nothing is Better than Something. Academy of Management Proceedings: 16683-16683.

Kumar, M. 1988. World geodetic system 1984: A modern and accurate global reference frame. Marine Geodesy 12: 117-126.

Kuppuswamy, V., and B.L. Bayus. 2017. Does my contribution to your crowdfunding project matter? Journal of Business Venturing 32: 72-89.

Kuppuswamy, V., and B.L. Bayus. 2018. Crowdfunding Creative Ideas: The Dynamics of Project Backers. In The Economics of Crowdfunding, ed. D. Cumming and L. Hornuf. Cham: Palgrave Macmillan.

Lee, E., and B. Lee. 2012. Herding behavior in online P2P lending: An empirical investigation. Electronic Commerce Research and Applications 11: 495-503.

Lévy, P. 1997. Collective Intelligence: Mankind's Emerging World in Cyberspace. Cambridge: Perseus Books.

Lin, M., and S. Viswanathan. 2016. Home Bias in Online Investments: An Empirical Study of an Online Crowdfunding Market. Management Science 62: 1393-1414.

Monteiro, N. 2018. The Case for Berlin's Claim as Europe's Startup Capital. https://www.entrepreneur. com/article/317953. Accessed 24 Apr 2019.

Moritz, A., J. Block, and E. Lutz. 2015. Investor communication in equity-based crowdfunding: a qualitative-empirical study. Qualitative Research in Financial Markets 7: 309-342.

Muchnik, L., S. Aral, and S.J. Taylor. 2013. Social Influence Bias: A Randomized Experiment. Science 341: 647-651.

Newey, W.K., and K.D. West. 1987. Hypothesis testing with efficient method of moments estimation. International Economic Review 28: 777-787.

O'Brien, R.M. 2007. A Caution Regarding Rules of Thumb for Variance Inflation Factors. Quality and Quantity 41: 673-690.

Ordanini, A., L. Miceli, M. Pizzetti, and A. Parasuraman. 2011. Crowd-funding: Transforming customers into investors through innovative service platforms. Journal of Service Management 22: 443-470.

Scharfstein, D.S., and J.C. Stein. 1990. Herd Behavior and Investment. Amercian Economic Review 80: 465-479.

Schwienbacher, A., and B. Larralde. 2012. Crowdfunding of Small Entrepreneurial Ventures. In The Oxford Handbook of Entrepreneurial Finance, vol. 13, ed. D. Cumming. Oxford: Oxford University Press.

Surowiecki, J. 2004. The Wisdom of Crowds: Why the Many are Smarter than the Few and How Collective Wisdom Shapes Business, Economies, Societies, and Nations. New York: Doubleday. 
van de Rijt, A., S.M. Kang, M. Restivo, and A. Patil. 2014. Field experiments of success-breeds-success dynamics. Proceedings of the National academy of Sciences of the United States of America 111: 6934-6939.

Vismara, S. 2018. Information Cascades Among Investors in Equity Crowdfunding. Entrepreneurship Theory and Practice 42: 467-497.

Vulkan, N., T. Åstebro, and M. Fernandez. 2016. Equity Crowdfunding: A New Phenomena. Journal of Business Venturing Insights 5: 37-49. https://doi.org/10.1016/j.jbvi.2016.02.001.

Zaggl, M.A., and J. Block. 2019. Do small funding amounts lead to reverse herding? A field experiment in reward-based crowdfunding. Journal of Business Venturing Insights 12: e00139.

Zhang, J., and P. Liu. 2012. Rational Herding in Microloan Markets. Management Science 58: 892-912.

Publisher's Note Springer Nature remains neutral with regard to jurisdictional claims in published maps and institutional affiliations. 